\title{
Students' Attitudes to Mathematics and Performance in Limits of Functions
}

\author{
Kristina Juter \\ Kristianstad University College, Sweden
}

\begin{abstract}
The main aim of this article is to discuss the attitudes to mathematics of students taking a basic mathematics course at a Swedish university, and to explore possible links between how well such students manage to solve tasks about limits of functions and their attitudes. Two groups, each of about a hundred students, were investigated using questionnaires, field notes and interviews. From the results presented a connection can be inferred between students' attitudes to mathematics and their ability to solve limit tasks. Students with positive attitudes perform better in solving limit problems. The educational implications of these findings are also discussed.
\end{abstract}

\section{Introduction}

When students learn a new mathematical concept or learn something further about an already known concept, they have to draw on parts of what they have already learnt or perhaps draw on related concepts. It is not only the mathematics per se that is recalled but also feelings and attitudes attached to the concept. The students' mathematical beliefs serve as a filter that influences mathematical thoughts and actions (Pehkonen, 2001). Thus in a learning situation students have to grapple not only with the new mathematics, but also with their own experiences, confidence, common sense and prior learning. Limits of functions are for many students difficult to understand because of the nature of the concept. Students often confuse limit values with function values, the notion of infinity is sometimes not understood correctly, the limit definition is difficult to understand and there is a possible confusion between limits as processes and as static objects (Cornu, 1991; Davis \& Vinner, 1986; Tall, 1980, 2001; Vinner, 1991). The multitude of challenges in learning about limits affect students in a number of possible ways, the most obvious one being that students who manage to overcome such barriers reinforce their positive attitudes and vice versa. But there are other possible scenarios, for example where students' perseverance drives them to work despite the influence of negative attitudes and prior failure or where students have positive attitudes to mathematics and still do not manage to learn about limits of functions because of other factors.

The purpose of this article is to identify students' attitudes to mathematics in general and to limits in particular as they progressed through a basic mathematics course, and to compare these attitudes to the students' abilities to solve limit tasks. The following questions will be addressed: 
- What are the students' attitudes to mathematics?

- What are the relations between these attitudes and the learning of limits of functions?

Two studies about students' development of the concept of limits of functions were conducted in 2002 (Juter, 2003). I wanted to determine the students' attitudes to mathematics first and then see how their conceptions of limits developed over a semester. The studies were conducted at a Swedish university. No such study has previously been conducted in Sweden.

\section{Theoretical background}

\section{Attitudes and beliefs}

Beliefs, attitudes and other related words are often used synonymously in the field of mathematics education (Leder \& Forgasz, 2002). Some researchers' choices and definitions of such words are presented below to exemplify their diverse use. Leder and Forgasz argued that meaningful research can still be done without a single, universally accepted definition.

McLeod (1992) speaks of stability in students' affective responses. Beliefs and attitudes are often considered to be relatively stable while emotions change more readily. He distinguished between beliefs, attitudes and emotions. Beliefs are described as the ways in which the students perceive mathematics or their own ability. One example is that "mathematics is about solving problems". Attitudes are, for example, dislikes of specific types of tasks. Emotions include the anxiety experienced in working through a proof.

Mohammad Yusof and Tall $(1994,1996)$ used "attitude" for all three words given by McLeod in their investigation of students' attitudes before and after a university course with an emphasis on cooperative problem solving and reflection on the thoughts of the problem solving process. The students, aged 18 to 21 years, were enrolled in different courses and constituted a mixture of third to fifth year undergraduates. They were asked to complete a two-part attitudinal questionnaire before and after the course and also after completing a traditional course in mathematics. The first part of the questionnaire dealt with attitudes to mathematics and the other with attitudes to problem solving. Mohammad Yusof and Tall reported that the students' attitudes were different before and after they had completed the more innovative course, but almost the same attitudes were displayed at the time of the first questionnaire and after the traditional course. These results suggest that students' attitudes are directly dependent on input from the surrounding environment, but any changes produced do not necessarily remain after the input causing the changes has stopped. However, the results in Mohammad Yusof and Tall's study may have been affected by the fact that the students were asked to respond to the same statements three times.

Students' attitudes that mathematics merely requires facts and procedures to be remembered emerged from the work of Mohammad Yusof and Tall $(1994,1996)$ as well as from Svege's (1997) study about students' 
beliefs, attitudes, and emotions concerning mathematics. Novak (1998), influenced by Ausubel, postulated a model of learning styles ranging from rote learning where there are no relations to existing knowledge, to meaningful learning where new knowledge is intentionally integrated in cognitive structures. Ausubel (2000) describes meaningful learning as "new symbolically expressed ideas (the learning task) [...] related in a non arbitrary, and non verbatim fashion, to what the learner already knows" (p. 67). Students who rely on rote learning in learning mathematics are typically more anxious about mathematical work than other students (Entwistle, 1998). Anxiety lowers the students' self confidence and the whole experience becomes unpleasant. Students who use rote learning are more likely to see the parts of mathematics they have learned as disjoint units of methods or rules, with the result that they can not see connections between different concepts or underlying crucial properties. Their mathematical understanding becomes weak and incomplete and it takes a lot of effort to sustain their mathematics studies as the pressure to remember rules, methods, theorems, and definitions mounts. Such a dysfunctional pattern is difficult to reverse since the students' foundational mathematical knowledge has gaps, which have to be filled, at least partially. If the gaps remain, there is, in some areas, nothing in the students' mental representations to which new knowledge can be connected. In such a case the new knowledge has no meaning for the students. They develop no sense of what is true and what is not.

An investigation (Szydlik, 2000) on students' beliefs and conceptual understanding revealed a connection between students' beliefs about how mathematical truth is established and the understanding of limits. Students who preferred authorities such as lecturers and textbooks to establish mathematical truth held inadequate definitions and misconceptions of limits to a higher degree than students who relied on intuition, logic and empirical evidence.

McLeod (1992) pointed to two different developments of attitudes. One comes from repeated emotional reactions to mathematics that become automatic, such as certain attitudes to a specific mathematical activity. The intensity of the emotional reaction will be weaker each time the situation occurs. The student's reaction is triggered by the situation rather than by actual emotions. The second development comes from assigning an existing attitude to a new, similar situation. A positive attitude to proofs in analysis can, for example, spread to a positive attitude to proofs in algebra. Attitudes and achievement have a relation that is complex and can not be described as one depending on the other (McLeod, 1992). Attitudes and confidence depend, on the other hand, strongly upon one another. Attitudes to mathematics indicate whether a student is confident working with mathematics. The confidence emerges from various personal experiences, derived from emotions, accomplishment, social settings and all other inner and outer stimuli. Therefore, it is important that all students experience success in their mathematics education. Students' own knowledge, or their 
perceptions of their own knowledge, is hence an important factor in attitudinal discussions.

The nature of knowledge as objective and subjective is discussed in Pehkonen (2001). Objective knowledge is the generally accepted structure within the mathematics community, while subjective knowledge is individual and based on personal experience and attainment. These types of knowledge are linked together and influence each other. Students taking a course in analysis simultaneously develop their mathematics and their attitudes towards the subject. Their subjective knowledge, affected by their attitudes, can influence the development in mathematics either in a positive way or in a negative way. If students think mathematics is all about formulas and counting, then it can be difficult for them to solve problems later on. Pehkonen compared systems of knowledge with systems of beliefs. Knowledge is often structured in a logical manner while beliefs have a tendency to occur in a quasi logical structure. This means that individuals use their own axioms and logic rules. These are not always the same as those used by mathematicians. Belief systems have two other distinctive features beside quasi logic. One is the psychological importance, which is the strength of the beliefs. The other feature is the beliefs' cluster structure, which means that the beliefs are gathered in clusters that do not have to be linked together directly. The structures of knowledge and beliefs, however, are linked together in mental representations.

\section{Mental representations and understanding}

A concept image is the total cognitive representation of a notion that an individual has in his or her mind (Tall \& Vinner, 1981). A concept can be represented in more than one way and there can even be conflicting representations that are evoked at different times, depending on the context. If the representations are not contradictory they can merge into one when the individual is able to see the connections (Dreyfus, 1991). If they are incoherent in any aspect, a conflict may arise. The incoherence can, for example, relate to interpretations of rules or perceptions of definitions in different contexts.

Mathematical representations can be compared to webs of mathematical concepts with connections between them (Novak, 1998). Attitudes influence the constructions of mental networks. If a specific concept is stimulating for a student, he or she is more likely to devote time and effort to work with it and compare it to other concepts. Then more and stronger links are made and that part of the concept image is more likely to make sense to the student. Even if not everything about the concept is clear, the time spent on working and trying to make sense of it strengthens the concept image. The influence goes in the opposite direction too, as constructions influence attitudes. The construction of the cognitive representations involves pattern recognition, categorisation and association (Hannula, 2002) and students' attitudes are dependent on how well they think they manage to come through the 
cognitive processes. The attitudes are also dependent on emotions, to a greater degree than on cognition (Hannula, 2002). Attitudes are hence an important factor in students' constructions of mental representations.

Hiebert and Carpenter (1992) define understanding of a mathematical concept to be something an individual has achieved when he or she can handle the concept as a part of a mental network, which is similar to Novak's (1998) and Ausubel's (2000) descriptions of meaningful learning. The more connections there are between mental representations, the better the individual understands the concept (Dreyfus, 1991; Hiebert \& Carpenter, 1992). If a concept is complicated in its nature, the connections become harder to make.

\section{The dual nature of limits of functions}

There is an ambiguity in the way the concept of limits can be perceived. One can focus on the process of approaching the limit and hence consider it a never ending procedure. But one can also think of the limit as a static entity, or object, to which functions can be compared. Sfard (1991) and Cottrill et al. (1996) have described theories of object formation from processes. A notion is first regarded as a process and when the characteristics of the notion become clear the notion can be seen as an object upon which other processes can be applied. These objects and processes form mental schemas to represent the concept and connections to it. Such schemas constitute individuals' concept images. Cottrill et al. (1996) concluded that the formal concept of a limit is an intricate dynamical schema and not a static one. It is important to have a strong dynamical conception of the notion before it is possible to embrace fully a more formal interpretation where the limit is seen as an object. In the development of refining the schema of limits there are leaps between seeing a limit as a process and as an object.

Limits are taught at upper secondary school in Sweden, but only in an informal intuitive manner with the focus on limits as processes. Therefore, the students have some conceptions of limits when they come to university. These conceptions can be difficult to change since they have been sufficient until the students started at the university. Hence these students do not feel a need to learn the formal definition (Williams, 1991) or to work further to understand the dual nature described above. Tsamir and Tirosh (2002) described intuitive beliefs as enduring self evident cognition forms. The strong feelings of certainty can cause a false sense of understanding.

\section{The study}

The questions explored in this study, as already indicated in the introduction, are:

- What are the students' attitudes to mathematics?

- What are the relations between these attitudes and the learning of limits of functions? 
The methods and instruments used in the study were both quantitative and qualitative, but the data presented in this article are mainly quantitative to give a clearer picture of possible patterns in the students' responses to the questions and tasks. In the data collection, students were variously considered as a group, and as individuals, to elicit as much information as possible about their attitudes to mathematics and knowledge of limits of functions. Details of the sample, methods and instruments are presented and discussed in this section.

\section{The sample}

The study was conducted in two stages with two different groups. The first group comprised 143 students who took part in the first part of the study in the spring semester of 2002. The following semester, autumn of 2002, 112 students participated in the second part of the study. About one third of the students were women, $36 \%$ in the first part and $29 \%$ in the second. All students were enrolled in a 20-week, full-time, basic level mathematics course covering algebra and analysis. Each group of students was taught by different teachers, one in algebra and one in analysis. The lectures were held three days per week with two lectures per day to the whole group. After the lectures, the students were separated into smaller groups for a teacher led problem solving session. I was not teaching any of the students and I did not know any of them.

The groups were slightly differently composed as the spring group had a larger number of students whose main interests were in biology, chemistry or some other non-mathematical topic. Students who study mathematics because their non-mathematical main interests require it are not likely to have attitudes as positive to mathematics as students with mathematics as their main topic of study. The differences in composition of the groups affected the study as we will see later in this article.

\section{Methods and data analysis}

The data were collected at three stages - stage A, stage B, and stage C - with each group of students. There were 132 students in the spring study and 99 students in the autumn study who responded to a questionnaire at stage A in the second week of the course. The questionnaire was designed to determine the students' attitudes to mathematics through seven attitudinal statements, and their knowledge about limits from upper secondary school through some easy limit tasks. Only the attitudinal part is described in this article to show the students' attitudes before limits were taught. The instruments used are discussed more fully in the next section. The students' responses were sorted, with data from the two groups kept separate. The students were individually categorised with respect to their responses to the attitudinal part of the questionnaire. The last four of the seven statements (see the instruments section) were used to categorise the students as "confident" or "unconfident". A typical "confident" student agreed with 
statements 5 and 7 and disagreed with statements 4 and 6. An "unconfident" student responded in the opposite way. Categorisation patterns were defined by at least three out of four consistent responses to these four statements. Students with some neutral responses to some of the statements but otherwise following one of the categorisation patterns were added to the relevant category. The aim with the categorisation was to be able to compare confident students' abilities to solve limit tasks with unconfident students' abilities to solve limit tasks. This categorisation of students does not take different degrees of confidence into account but, as will be shown further on, a majority of the students could be categorised by this method. Limits were introduced to the students between stage $A$ and stage $B$.

At stage B, in the fifth week of the course, 106 of the students in the spring study responded to a second questionnaire with limit tasks and attitudinal questions. The attitudinal part, as described in the instruments section, included four open questions about what the students found most interesting, stimulating and difficult in the course. From the answers to these four questions, the most commonly mentioned concepts were listed to show which concepts the students thought of in the given contexts. The instruments used in the two groups were not identical. One reason for this was that some tasks were trialled in the spring study. The students in the autumn course were not asked the four questions because of time constraints. This was the only difference in the instruments used in the study described in this article. However, the responses to the four items are relevant for the questions posed in this article; hence they are included in the data.

The students in both groups responded to a questionnaire at stage $C$ in the seventh week of the course. The questionnaire comprised two tasks about limits with given solutions, which are described in the instruments section. Solutions were given by 87 students from the spring study and 78 students from the autumn study. The tasks are called Task 1 and Task 2 in a later section of the article. The students' solutions to the tasks were transcribed and put into a computer program for categorisation. In this article I will only use the categories representing complete and correct solutions to measure the students' abilities to solve limit tasks. Examples of student solutions and expected solutions are provided in later sections.

The number of students in the groups and the methods used at the three stages are summarised in Table 1. 
Table 1

Number of students enrolled, instruments used and time at each stage

\begin{tabular}{lcccc}
\hline & Spring group & Autumn group & Instruments & Time \\
\hline Stage A & 132 & 99 & Attitudinal tasks & Second week \\
Stage B & 106 & - & Attitudinal tasks & Fifth week \\
Stage C & 87 & 78 & Limit tasks & Seventh week \\
\hline
\end{tabular}

Field notes were taken for both groups to shed some light on the students' activities during lectures and in the classroom where tasks were solved. Students were together for the lectures but were divided into smaller groups with 20 to 30 students for the task solving sessions. I followed one such group and almost all the lectures, as an observer, when they were dealing with limits. The field notes were organised so that each student was represented by a square in a grid representing the classroom at the group sessions, and all actions such as asking questions, solving tasks at the black board or commenting on something were written down to give a picture of the activities during each lesson. The students were less active during the lectures and there were too many students to consider them individually. Therefore, the data collection at the lectures consisted of notes of what the lecturer presented and questions and comments from the students.

Fifteen of the students in the autumn study were interviewed on two different occasions to capture as many individual experiences as possible (Juter, 2003). The results of the interviews are not presented in this article.

\section{Instruments}

The students responded to a questionnaire in the beginning of the semesters, at stage A. The following statements, based on Mohammad Yusof and Tall (1994), were part of the questionnaire.

1. Mathematics is a collection of facts and processes to be remembered.

2. Mathematics is about solving problems.

3. Mathematics is about coming up with new ideas.

4. I learn mathematics through rote learning.

5. I usually understand a mathematical idea quickly.

6. I have to work very hard to understand mathematics.

7. I can connect mathematical ideas that I have learned. 
The students had five possible responses for each given proposition. They indicated with:

- $\quad$ if they agreed strongly,

- $y$ if they agreed,

- $\quad$ if they neither agreed nor disagreed,

- $\mathrm{n}$ if they disagreed, and

- $\quad \mathrm{N}$ if they strongly disagreed.

The questionnaires also contained questions about limits of functions.

The students in the spring course were asked the following questions at stage B:

1. What has been the most important thing you have learned in the analysis part of the course to date?

2. What has most stimulated you in the analysis part of the course to date?

3. What has been hardest to understand?

4. Write what you still do not understand.

The questions were designed to allow the students to express their priorities and experiences of mathematics in general. The overall purpose was to see how the students mentioned limits of functions among other mathematical concepts.

The questionnaire at stage $\mathrm{C}$ contained tasks about limits of functions for the students to solve. The questionnaire comprised tasks with presented solutions and tasks without solutions. The solutions were given to challenge the students to react, i.e., either to agree or to come up with alternative solutions. If a task was too difficult at first sight and there was no pressure to produce a solution, the students could leave it unsolved. But an attempt at a solution or a whole solution might stimulate some sort of response from the students. The two following tasks with solutions were given to both groups.

Task 1: Problem: Decide the following limit value: $\lim _{x \rightarrow 1} \frac{x^{2}+x}{x^{2}-1}$.

Solution: $\frac{x^{2}+x}{x^{2}-1}=\frac{x(x+1)}{(x-1)(x+1)}=\frac{x}{x-1} \rightarrow \infty$ when $x \rightarrow 1$.

Adjustments (What will change or be completed and why).

Task 2: Problem: Decide the following limit value: $\lim _{x \rightarrow \infty} x \sin \left(\frac{2}{x}\right)$.

Solution: $x \sin \left(\frac{2}{x}\right)=\frac{\sin \left(\frac{2}{x}\right)}{\frac{1}{x}}$. We know that $\frac{2}{x} \rightarrow 0$ when $x \rightarrow \infty$ and $\frac{1}{x} \rightarrow 0$ when $x \rightarrow \infty$. The limit value $\lim _{x \rightarrow \infty} \frac{\sin x}{x}=1$ implies that $\frac{\sin \left(\frac{2}{x}\right)}{\frac{1}{x}} \rightarrow 1$ when $x \rightarrow \infty$.

Adjustments (What will change or be completed and why). 
In Task 1 the students were expected to calculate left and right limit values and to see that they are not the same. The given solution to Task 2 does not compensate for the constant 2 and the students were expected to rewrite the function, $\frac{\sin \left(\frac{2}{x}\right)}{\frac{1}{x}}=\frac{\sin \left(\frac{2}{x}\right)}{\frac{2}{x}} \cdot 2$, and then use the standard limit value in the given solution.

\section{Results}

\section{The attitudinal statements at stage $A$}

The statements from the questionnaires and the results of the students' responses are presented in Table 2. The numbers do not add up to $100 \%$, because not all the students responded to all the statements.

\section{Table 2}

Percentage responses to the attitudinal questions: Spring study 2002 and Autumn study 2002.

\begin{tabular}{|c|c|c|c|c|c|c|c|}
\hline \multicolumn{3}{|c|}{ Statement } & \multirow{2}{*}{$\frac{Y}{10}$} & \multirow{2}{*}{$\frac{y}{43}$} & \multirow{2}{*}{$\frac{-}{15}$} & \multirow{2}{*}{$\frac{n}{21}$} & \multirow{2}{*}{$\begin{array}{c}\mathrm{N} \\
10\end{array}$} \\
\hline 1. & Mathematics is a collection of facts & Spring & & & & & \\
\hline & and processes to be remembered. & Autumn & 3 & 34 & 16 & 28 & 16 \\
\hline \multirow[t]{2}{*}{2} & Mathematics is about solving & Spring & 57 & 40 & 1.5 & 1.5 & 0 \\
\hline & problems. & Autumn & 45 & 42 & 7 & 2 & 2 \\
\hline \multirow[t]{2}{*}{3} & Mathematics is about coming up & Spring & 17 & 39 & 27 & 15 & 1.5 \\
\hline & with new ideas. & Autumn & 17 & 45 & 26 & 6 & 3 \\
\hline \multirow[t]{2}{*}{4 . } & I learn mathematics through rote & Spring & 3.1 & 21 & 16 & 37 & 21 \\
\hline & learning. & Autumn & 0 & 19 & 15 & 46 & 18 \\
\hline \multirow[t]{2}{*}{5.} & I usually understand a mathematical & Spring & 10 & 30 & 27 & 28 & 3.8 \\
\hline & idea quickly. & Autumn & 6 & 39 & 23 & 24 & 4 \\
\hline \multirow[t]{2}{*}{6.} & I have to work very hard to & Spring & 10 & 35 & 18 & 27 & 9 \\
\hline & understand mathematics. & Autumn & 10 & 25 & 29 & 23 & 11 \\
\hline \multirow[t]{2}{*}{7.} & I can connect mathematical ideas & Spring & 14 & 50 & 25 & 10 & 0.8 \\
\hline & that I have learned. & Autumn & 10 & 62 & 22 & 5 & 0 \\
\hline
\end{tabular}


The two groups of students had very similar responses to the questionnaire, though there are small variations. A larger proportion of the students in the spring study agreed with statements 1, 2, 4 and 6 than of the students in the autumn study. A larger proportion of the students in the autumn study agreed with statements 3,5 and 7 . According to these numbers, the students in the autumn study were slightly more confident about their own abilities in mathematics, which is not surprising since a number of students in the spring group did not have mathematics as their main field of study.

About $45 \%$ of the students considered mathematics to be facts and processes to be remembered, as in the studies by Mohammad Yusof and Tall (1994) and Svege (1997). More than $90 \%$ of the students thought that mathematics was about solving problems and $60 \%$ of them agreed with the statement that mathematics is about coming up with new ideas $(27 \%$ of the students were neutral on this statement). Around $60 \%$ of the students stated that they do not learn mathematics through rote learning but over $20 \%$ claimed to do so and 15\% were neutral. In contrast to the results of this study, $75 \%$ of the students in Mohammad Yusof and Tall's (1994) study claimed to learn by rote.

There were nearly as many students who claimed to understand a mathematical idea quickly (statement 5) as there were in agreement with the opposite statement. The same goes for the number of students who had to work hard to understand mathematics (statement 6). Most students stated that they could connect mathematical ideas that they have learned (statement 7).

\section{The four questions at stage B}

The questions were answered by 106 students, and the most frequently mentioned concepts are listed in Table 3.

\section{Table 3}

Students' responses to the four questions in the spring group. Number and (\%).

$\begin{array}{ccccc}\text { Concepts } & \begin{array}{c}\text { 1. Most } \\ \text { important }\end{array} & \begin{array}{c}\text { 2. Most } \\ \text { stimulating }\end{array} & \begin{array}{c}\text { 3. Hardest to } \\ \text { understand }\end{array} & \begin{array}{c}\text { 4. Still do not } \\ \text { understand }\end{array}\end{array}$

\begin{tabular}{lcccc}
\hline Limits & $25(24)$ & $8(8)$ & $58(55)$ & $35(33)$ \\
Trigonometry & $18(17)$ & $14(13)$ & $13(12)$ & $5(5)$ \\
Derivatives & $5(5)$ & $1(1)$ & $2(2)$ & $1(1)$ \\
Functions & $4(4)$ & $2(2)$ & $7(7)$ & $4(4)$ \\
Proofs & $7(7)$ & $4(4)$ & $11(10)$ & $5(5)$ \\
Diophantic equations & - & $8(8)$ & $2(2)$ & $3(3)$ \\
Complex numbers & $4(4)$ & $4(4)$ & $1(1)$ & $2(2)$ \\
\hline
\end{tabular}


The data presented in Table 3 indicate the students' perceptions of the mathematics in the course. Limits are considered to be the most important and hardest to understand but not the most stimulating by this group of students. The last two concepts in the table were taught in the algebra part of the course and not in the analysis part, but the students mentioned them here anyway.

\section{Task 1 and Task 2 at stage $C$}

Table 4 displays the percentages of the students in each group who were able to solve the tasks completely and correctly. There were 87 students in the spring group and 78 in the autumn group involved in this part of the study.

\section{Table 4}

Percentage of the students solving the tasks completely and correctly.

\begin{tabular}{lcc} 
& Spring group & Autumn group \\
\hline Task 1 & 21 & 36 \\
Task 2 & 11 & 21 \\
\hline
\end{tabular}

As expected, the students in the autumn study show better results in solving these two tasks.

One common error, which $17 \%$ of the spring group and $15 \%$ of the autumn group made, was to use a method which works for rational functions when $\mathrm{x}$ tends to infinity but not when $\mathrm{x}$ tends to one as in Task 1 . An example of a student solution of this type is the following:

$$
\frac{x^{2}+x}{x^{2}-1}=\frac{x^{2}\left(1+\frac{1}{x}\right)}{x^{2}\left(1-\frac{1}{x^{2}}\right)} \rightarrow \frac{1+1}{1-1} \rightarrow \infty
$$

The limit process is taken in two steps where the problem with different left and right limit values is ignored.

As is indicated by the data in Table 4, Task 2 was more difficult for the students to solve. The most commonly used method was to reason in terms of infinity, often locally, which means that the students did not regard the features of the whole function as $x$ tends to infinity. For example:

$\frac{1}{x} \rightarrow 0$ when $x \rightarrow \infty$ so the denominator has to go $\rightarrow \infty$ and the expression $\rightarrow \infty$. 
The results so far have focussed on the groups as such and not on the students as individuals. It is interesting to see how students strongly confident in their own capability coped with the tasks compared to students with weak self-confidence. The categorisation described in the method section gave the result that $61(47 \%)$ students from the spring study and 54 (55\%) students from the autumn study were categorised as "confident" and $28(21 \%)$ students from the spring study and $16(16 \%)$ students from the autumn study were categorised as "unconfident". This shows again that the autumn students were more confident. Not all students solved the tasks. There were 35 from the 61 "confident" spring students, 17 from the 28 "unconfident" spring students, 36 from the 54 "confident" autumn students and 9 from the 16 "unconfident" autumn students who did. Table 5 shows the results of the students' success at solving the tasks with respect to their overall confidence in mathematics.

Table 5

Number and (\%) of correct solutions to Task 1 and Task 2 by students who responded to both statements and tasks.

\begin{tabular}{lcccc} 
Task & $\begin{array}{c}\text { Confident: } \\
\text { Spring }\end{array}$ & $\begin{array}{c}\text { Unconfident: } \\
\text { Spring }\end{array}$ & $\begin{array}{c}\text { Confident: } \\
\text { Autumn }\end{array}$ & $\begin{array}{c}\text { Unconfident: } \\
\text { Autumn }\end{array}$ \\
\hline Task 1 & $5(14)$ & $2(12)$ & $13(36)$ & $2(22)$ \\
Task 2 & $6(17)$ & $1(6)$ & $9(25)$ & $0(0)$ \\
Total number of students & 35 & 17 & 36 & 9 \\
\hline
\end{tabular}

The "confident" students in the autumn study had a higher rate of correct answers than did the "confident" students in the spring study. The results of the "unconfident" students' task solving are not very clear, which may be explained by having too few students in these categories.

\section{The field notes}

The field notes revealed that the students were not very active during lectures or in class. There were not many questions or remarks from the students during the lectures that I observed. The task solving lessons were planned for the students to solve problems at the blackboard, with a teacher helping if necessary, but the students' unwillingness to do that often left the teacher solving the students' problems.

In the autumn study the teacher at the task solving sessions asked the students about the limit tasks. The first question to the students was whether they found the limit value tasks harder than the other tasks. The answer from the class was yes. They said that they had not met epsilons and deltas before and this was hard for them to understand. The second time was two days 
later when the teacher asked if the students found a specific kind of task harder than tasks that involved only calculation. The students said that they did and that they preferred to use standard limit values. The specific task was a function, $\frac{x+7}{x-3}$, that was supposed to be proved, with the limit value definition, to be continuous at $x=2$. Not all students participated in the discussion.

\section{Discussion}

The results from the previous section, together with the theoretical background, are used to address the research questions: What are the students' attitudes to mathematics? What are the relations between these attitudes and the learning of limits of functions? The questions are discussed under three headings relating to students' abilities to solve limit problems, understanding of the limit concept, and attitudinal changes. Educational implications are linked to the discussion under each heading.

\section{Students' abilities to solve problems}

The results of this study suggest that there is a connection between students' positive or confident attitudes to mathematics and their ability to solve limit tasks successfully. Which one depends on the other is not possible to tell from this study and perhaps not at all (McLeod, 1992). The results from the groups presented in Table 4, as well as from the students as individuals in Table 5, imply that students with positive confidence perform better in solving problems about limits of functions, or that students who are capable of solving problems have a positive attitude to mathematics. Mohammad Yusof and Tall $(1994,1996)$ also reported that students participating in a course with an emphasis on problem solving processes showed more positive attitudes to mathematics and problem solving. Thus when teaching limits of functions in particular, it seems important to ensure that the students' learning environment offers varied opportunities for discussion and problem solving. In that way students can consolidate their current knowledge and be stretched to enhance their skills. There are several students who claimed that they had to work very hard to understand mathematics (statement 6 in Table 2), and that they did not understand a mathematical idea quickly (statement 5). Examples of this were found in the field notes. One student had solved a task at the blackboard during a problem solving session. He used the limit definition. When he was finished, he asked the teacher: "What have I proved?". Other students in the group agreed with him and they thought it was hard to know when something was proved with the limit definition. So although the students worked with the suggested tasks, they did not always understand how they used the mathematics. On the other hand, there were almost no students who stated that they could not connect mathematical ideas they had learned (statement 
7). The responses to these three statements (statements 5,6 and 7) are both encouraging and dispiriting. The result of the first two of them suggests that if students have time to spend on mathematics, then they can learn it. But the third statement (statement 7) can also be true. If an individual does not have the time or inclination to work, then there can not be a successful connection between the new and the existing mathematical parts in the concept image (Tall \& Vinner, 1981). Perhaps students do not see the new parts as learned if they are not fully integrated with the mental networks of mathematics.

\section{Aspects of understanding}

The fact that so many students in the present study, as well as in Mohammad Yusof and Tall's (1994) and Svege's (1997) studies, see mathematics as something to be remembered indicates that understanding is not the goal of the students' learning processes or perhaps of the teaching. This is emphasised by the statement that mathematics is about solving problems. It seems that the students' efforts are focused on the problems and solution methods rather than on the theory. This situation is an example of Pehkonen's (2001) description of the influence of beliefs on the learning of mathematics, where the students' subjective knowledge interferes with their objective knowledge. But the students' ideas of what constitutes a mathematical problem are not clear. It can be any task or something that is not trivial for the students to solve (Schoenfeld, 1992). If students think that mathematical problems are not only to find solutions to tasks, but also to justify conjectures or to understand proofs, then I would not say that the theory part is neglected. The field notes show that most students did not want to solve problems in class. Apart from the tasks being too difficult for the students, there can be other reasons for this, for example doubt about their own mathematical ability or shyness. These problem solving sessions also affect students' attitudes. Confident and successful students who solve tasks in front of the class strengthen their positive attitudes, while inactive students with low mathematical self-confidence do not get, or take, the opportunity to feel success through interactions with peers.

The responses to statement 3 (Table 2) stand in contrast to a shallow view of mathematics, as quite a few students thought that mathematics was about coming up with new ideas. If students only work with standard tasks and do not consider the underlying theory, then they will probably find it hard to discover new things. There is a better chance for them to get new ideas if they are bold and explore the features of the processes and objects on which they are working rather than just rely on texts and lecturers' words. Szydlik (2000) claimed bold students are more likely to have accurate conceptions of limits of functions. The students are certainly aware that they should be prepared to explore new approaches and perhaps want to work in that way, but understanding often takes time, and time has a tendency to run out. A strategic selection of what to study can favour routine-tasks and rote learning (Mohammad Yusof \& Tall, 1994). Courses are often assessed with 
similar tasks, so the choice to skip theory is not surprising. Theorems and proofs can be learned by heart as well; in this way it might seem as if a student has understood a concept even if that is not the case. About $60 \%$ of the students in this study claimed not to learn by rote, which implies that there is a rather large number of students who do.

If a student is learning limits of functions by rote, what are the specific features that he or she will remember? Many students find limits of functions to be difficult to understand as we have shown before. Selecting the appropriate method to use when dealing with limits is often not trivial. The formalistic formulation of the definition, and for many students the new way of thinking, compound the difficulties. If students are unable to see and understand the concept's critical features, then they do not know what to learn by heart. They see that several methods are present in textbooks and at lectures and feel pressured to make sense of them all, which possibly adds to their anxiety (Entwistle, 1998). There are methods that are systematically used, which students learn and remember, for example to use the dominant term when they work with rational functions where the independent variable tends to infinity. The students in the autumn study had learned that method for rational functions and then they got a rational function where the independent variable tended to one. Many of the students started to divide by the dominant term, which is the term that would have dominated if $\mathrm{x}$ tended to infinity, even though it did not help them to solve the problem. They had simply recognised a rational function as a surface property, and they did not remember why they used the method with the dominant term. This illustrates the danger of learning a method without fully understanding it.

\section{Attitudinal changes}

The notion of limits of functions is such that it takes time and effort for most students to understand fully the meaning of the concise formalised definition and to integrate it with their existing mental representations (Cornu, 1991; Davis \& Vinner, 1986; Juter, 2003, 2004; Szydlik, 2000; Tall \& Vinner, 1981; Williams, 1991). Students have to devote a lot of energy and, if they are excited and curious about the subject, there is something that drives them to make sense of what they work with. If their first experiences with limits are positive, then the attitudinal development triggered by emotional reactions (McLeod, 1992) has a chance to grow strong (Pehkonen, 2001) and be sustained during the demanding nature of the learning process. One outcome of Mohammad Yusof and Tall's $(1994,1996)$ study was that even though attitudinal changes did occur, the attitudes tended to change back again after some time. The information summarised in Table 3 indicates that limits of functions are considered to be important, but very hard to understand, so these attitudes have a strong psychological importance (Pehkonen, 2001). Hence there has to be strong positive experiences for the students to change such attitudes and maintain the changes. 
Intuitive beliefs (Tsamir \& Tirosh, 2002) that are inconsistent with the formal concept definition are possible causes for misplaced high selfconfidence. Intuitive beliefs need to be challenged to bring students to understand that there is much more about limits to investigate and make sense of. This in turn can get the students to lose their confidence, not only about limits but about their total ability to work with mathematics. This is, however, a necessary risk to be taken if students are to get a chance to create true and rich concept images (Tall \& Vinner, 1981), and to understand their meaning (Dreyfus, 1991; Hiebert \& Carpenter, 1992). As I see it, the teacher's role involves giving a balanced challenge so that students experience the need to modify their concept images intertwined with moments of success in order to maintain or develop positive attitudes towards mathematics.

This study traced students' attitudes and abilities measured at separate, distinct times. This approach may prevent changes that take place between periods of data collection being detected. If students successfully construct their cognitive representations over a period of time, then their attitudes to mathematics are likely to become more positive (Hannula, 2002). When they strike a problem, the positive attitudes become less positive, or more negative. There can then be several sets of attitudinal clusters or clusters of beliefs (Pehkonen, 2001) which are connected to the different contexts in which they were created. The clusters can be disjoint and, depending on the input from questions or elsewhere, the students evoke different clusters; this might confound the findings in the data collected. Therefore, it is important to keep in mind the different stages of the course when the data were collected. The data presented in Table 2 were gathered before the students had worked with limits in the course. The rest of the results presented are from the time after limits of functions had been presented and many of the students struggled to integrate this new material with what they already knew.

The students' attitudes described in this article are what lecturers and teachers have to consider in their classrooms. The students have developed these attitudes through many years of schooling and they are not easily changed over a semester. Most changes do not occur without effort. Therefore, for changes to occur, explicit attempts must be made by the teacher and the student.

\section{Conclusions}

To answer the first of the research questions (What are the students' attitudes to mathematics?), a majority of the students considered mathematics to be facts and processes to remember and mathematics to be about solving problems but also about coming up with new ideas. Most students claimed not to learn by rote. The majority of the students stated that they could synthesise mathematical ideas that they had learned, but many students had to work very hard to understand mathematics. Limits of functions were regarded to be most important in the analysis course, but also most difficult 
to understand. This implies that most students in the study had to work hard to integrate the new knowledge to existing concept images. The fact that they thought limits were important probably encouraged them not to give up their attempts to learn limits.

To address the second question (What are the relations between these attitudes and the learning of limits of functions?), the results of the study show that confident students perform better in solving limit problems than unconfident students do. The students' attitudes were contradictory at some points. Students who claimed to be able to connect mathematical ideas they have learned, but who regard mathematics to be facts and processes to remember can have a meaningful learning approach if they see remembering as a synonym for learning. If they have a rote learning strategy instead, the connections to other mathematical ideas are likely to be weak and based on first sight similarities as exemplified in this study.

The results from the present study provide teachers with evidence of students' efforts to learn limits, and of their attitudes to mathematics. The relationship between attitudes and achievement in solving limit problems implies that time should be spent on enhancing positive attitudes. Since so many $(55 \%)$ of the students in the spring study found limits to be the hardest part of the analysis course to understand, there is reason to work through limits thoroughly and use various problems at different levels to help students understand the concept's features, and hence to be able to make strong and meaningful mental connections to other concepts.

Acknowledgement: I want to thank Professor Gilah Leder and several anonymous reviewers for their comments and helpful suggestions on earlier drafts of this article.

\section{References}

Ausubel, D. P. (2000). The acquisition and retention of knowledge. Dordrecht: Kluwer Academic Publishers.

Cornu, B. (1991). Limits. In D. Tall (Ed.), Advanced mathematical thinking (pp. 153-166), Dordrecht: Kluwer Academic Publishers.

Cottrill, J., Dubinsky, E., Nichols D., Schwingendorf, K., Thomas, K., \& Vidakovic, D. (1996). Understanding the limit concept: Beginning with a coordinated process scheme. Journal of Mathematical Behaviour, 15, 167-192.

Davis, R., \& Vinner, S. (1986). The notion of limit: Some seemingly unavoidable misconception stages. Journal of Mathematical Behavior, 5, 281-303.

Dreyfus, T. (1991). Advanced mathematical thinking processes. In D. Tall (Ed.), Advanced mathematical thinking (pp. 25-41). Dordrecht: Kluwer Academic Publishers.

Entwistle, N. (1998). Approaches to learning and forms of understanding. In B. Dart \& G. Boulton-Lewis (Eds.), Teaching and learning in higher education (pp. 72-101), Melbourne: The Australian Council for Educational Research Ltd.

Hannula, M. (2002). Attitude towards mathematics: Emotions, expectations and values. Educational Studies in Mathematics, 49(1), 25-46. 
Hiebert, J., \& Carpenter, T. P. (1992). Learning and teaching with understanding. In D. A. Grouws (Ed.), Handbook of research on mathematics teaching and learning (pp. 65-97). New York: Macmillan.

Juter, K. (2003). Learning limits of function: University students' development during a basic course in mathematics. (Licentiate thesis) Luleå: Luleå University of Technology, Department of Mathematics.

Juter, K. (2004). Limits of functions - How students solve tasks. In C. Bergsten (Ed.), Proceedings of MADIF 4, the 4th Swedish Mathematics Education Research Seminar (pp. 146-156). Malmö, Sweden: Swedish Society for Research in Mathematics Education.

Leder, G., \& Forgasz, H. (2002). Measuring mathematical beliefs and their impact on the learning of mathematics: A new approach. In G. Leder, E. Pehkonen, \& G. Törner (Eds.), Beliefs: A hidden variable in mathematics education? (pp. 95-114), Dordrecht: Kluwer Academic Publishers.

McLeod, D. (1992). Research on affect in mathematics education: A reconceptualization. In D. Grouws (Ed.), Handbook of research on mathematics teaching and learning (pp. 575-593), New York: Macmillan Publishing Company.

Mohammad Yusof, Y., \& Tall, D. (1994). Changing attitudes to mathematics through problem solving. In J. Pedro da Ponte \& J. Filipe Matos (Eds.), Proceedings of the 18th conference of the International Group for the Psychology of Mathematics Education (Vol. 4, pp. 401-408), Lisbon: Departamento de Educação, Faculdade de Ciências da Universidade de Lisboa.

Mohammad Yusof, Y., \& Tall, D. (1996). Conceptual and procedural approaches to problem-solving. In L. Puig \& A. Gutierrez (Eds.), Proceedings of the 20th conference of the International Group for the Psychology of Mathematics Education (Vol 4, pp. 3-10), Valencia: Universitat de València. Departement de Didàctica de la Matemàtica.

Novak, J. D. (1998). Learning, creating, and using knowledge. New Jersey: Lawrence Erlbaum Associates, Publishers.

Pehkonen, E. (2001). Lärares och elevers uppfattningar som en dold faktor i matematikundervisningen. In B. Grevholm (Ed.), Matematikdidaktik - ett nordiskt perspektiv (pp. 230-253), Lund, Sweden: Studentlitteratur.

Schoenfeld, A. (1992). Learning to think mathematically: Problem solving, metacognition and sense-making in mathematics. In D. Grouws (Ed.), Handbook for research on mathematics teaching and learning (pp. 334-370). New York: Macmillan.

Sfard, A. (1991). On the dual nature of mathematical conceptions: Reflections on processes and objects as different sides of the same coin. Educational Studies in Mathematics, 22, 1-36.

Svege, E. (1997). Studenters forestillinger, holdninger og følelser overfor matematikk. Nordisk Matematikkdidaktikk, 2, 25-53.

Szydlik, J. (2000). Mathematical beliefs and conceptual understanding of the limit of a function, Journal for Research in Mathematics Education, 31(3), 258-276.

Tall, D. (1980). Mathematical intuition, with special reference to limiting processes. Proceedings of the Fourth International Congress on Mathematical Education, Berkeley, 170-176.

Tall, D. (2001). Natural and formal infinities. Educational Studies in Mathematics, 48, 199-238. 
Tall, D., \& Vinner, S. (1981). Concept image and concept definition in mathematics with particular reference to limits and continuity. Educational Studies in Mathematics, 12, 151-169.

Tsamir, P., \& Tirosh, D. (2002). Intuitive beliefs, formal definitions and undefined operations: Cases of division by zero. In G. Leder, E. Pehkonen, \& G. Törner (Eds.), Beliefs: A hidden variable in mathematics education? (pp. 331-344), Dordrecht: Kluwer Academic Publishers.

Vinner, S. (1991). The role of definitions in the teaching and learning of mathematics. In D. Tall (Ed), Advanced mathematical thinking (pp. 65-81). Dordrecht: Kluwer Academic Publishers.

Williams, S. (1991). Models of limit held by college calculus students. Journal for Research in Mathematics Education, 22(3), 219-236.

\section{Author}

Kristina Juter, Kristianstad University College, Department of Mathematics and Science, 291 88, Kristianstad, Sweden. Email: <Kristina.Juter@mna.hkr.se> 